\title{
Sense Perception and Testimony in the Gospel According to John
}

[Sinneswahrnehmung und Zeugnis im Johannesevangelium.]

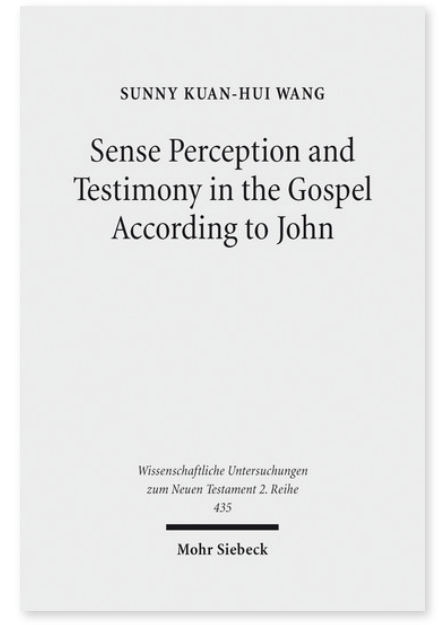

2017. XV, 257 Seiten. WUNT II 435

ISBN 978-3-16-155115-4

DOI 10.1628/978-3-16-155115-4

eBook PDF 94,00€

ISBN 978-3-16-154735-5

fadengeheftete Broschur $94,00 €$
Veröffentlicht auf Englisch.

Sunny Kuan-Hui Wang untersucht in diesem Buch die Beziehung zwischen Sinneswahrnehmung und Zeugnis im Johannesevangelium. Während Johannesforscher sich zumeist entweder auf das Eine oder das Andere konzentrieren, zeigt sie, dass Sinneswahrnehmung und Zeugnis beide wichtig sind und gemeinsam verwendet werden, um die Leser in die Erzählung hineinzuziehen, um sie auf emotionaler Ebene zu Zeugen zu machen. Es wird behauptet, dass Johannes' Umgang mit der Sinneswahrnehmung in Verbindung mit dem Zeugnis in der jüdischen Literatur verwurzelt ist. Johannes verwendet aber auch eine rhetorische Methode der Griechen und Römer, enargeia, welche die Überzeugungskraft der

Sinneswahrnehmung anspricht, um seine Erzählung anschaulich zu machen. Johannes spielt die Sinneswahrnehmung nicht herunter. Stattdessen verwendet er sie im Kontext des Zeugnisses als ein Überzeugungsmittel, um seine Leser im Geiste in die Erfahrungen der ersten Jünger, und damit tiefer in den Glauben und das Zeugnis, hineinzuziehen.

Sunny Kuan-Hui Wang Born 1975; since 2014 Assistant Professor of New Testament at the Central Taiwan Theological Seminary.

\section{Jetzt bestellen:}

https://mohrsiebeck.com/buch/sense-perception-and-testimony-in-the-gospel-according-to-john-9783161551154?no_cache=1 order@mohrsiebeck.com

Telefon: $+49(0) 7071-923-17$

Telefax: $+49(0) 7071-51104$ 